\section{PROVINCIAL HOSPITAL REPORTS.}

\section{WORTHING INFIRMARY.}

A CASE OF FORMIDABLE INJURY OF THE FOOT ; RECOVERY UNDER THE ANTISEPTIC TREATMENT.

(Under the care of Dr. JoHN GoLDsMith.)

Georan L—, a labourer's child, three years of age, was admitted with a very severe wound of the right foot, which he had sustained through its becoming engaged in a moving mowing machine. On examination it was found that one of the blades had entered the dorsum of the foot at the anterior portion of the astragalus, immediately in front of the attachment of the anterior ligament (thus fortunately not opening the ankle-joint), and had passed obliquely downwards and backwards, entirely dividing the anterior portion of the os calcis, so that the foot was simply hanging by the soft parts of the sole. The next blade, rapidly following the first, had sliced off the cartilaginous structures of the astragalo-scaphoid articulation.

After a consultation it was decided, not without considerable misgiving, to endeavour to save the foot.

The patient having been brought under the influence of chloroform, the anterior tibial artery, which had fortunately ceased to bleed when the wound was first bound up, and another smaller vessel were tied, and several fragments of bone and cartilage and some pieces of grass were carefully removed. The whole of the wounded surfaces were then abundantly smeared with glycerine of carbolic acid, and their edges brought into accurate apposition by means of silver sutures; no adhesive plaster was used. A double fold of lint, thoroughly saturated with glycerine of carbolic acid, was laid over the whole line of sutures, and lightly secured by one or two turns of a bandage. Splints of Hide's patent leather felt were then moulded to the leg; the inner one was prolonged round the sole in order to keep the foot at the proper angle, and both were carried half-way up the thigh in order to prevent all movement at the knee-joint. This precaution was the more necessary as the young patient was suffering from whooping-cough. The whole limb was bandaged, and a sand-bag was placed on either side.

At the end of ten days it was found, on removing the dressings for the first time, that a very considerable amount of union had taken place, and that there was literally no suppuration. The ligatures and sutures were then removed, similar dressing applied, and the limb put up again as before. After eight days more the external wound was found to be almost entirely healed, and no trace whatever of suppuration existed. In a few days there was complete external union, but the foot was kept in the same apparatus for the space of eight weeks. A boot with lateral supports was then ordered, and with this the patient was allowed to attempt to walk with the assistance of the nurse. From that time to the present (the eightieth day) he bas rapidly improved, and can now walk and run unaided almost as well as before the accident. He flexes and extends the foot and toes as well as ever, thus showing how complete has been the union of all the divided tendon. It is anticipated that in a few Jears there will be no trace of the misfortune, except the mark of the external wound.

\section{NEWCASTLE-ON-TYNE INFIRMARY.}

OPERATIONs were performed as follows at the Infirmary, Newcastle-on-Tyne, on the 10 th inst. :-

Dr. Hwath removed the breast from a married woman twenty-nine years of age. In February last the patient noticed a swelling of the size of an egg in her left breast. The tumour enlarged rapidly, but without much pain, and occasionally blood flowed from the nipple. Early in August, in consequence of the large size of the breast, and a very copious discharge of blood from the nipple, the patient consulted Dr. Heath, who evacuated about a pint of thin, bloody fluid, and injected tincture of iodine. This treatment was repeated on two other occasions. At the time of removal there was at the seat of puncture a fungoid ulcer the size of a florin, through which a thin, slightly bloody, coloured, and most offensive fluid constantly flowed guttatim. There was no family history of malignant disease. Upon examination after removal, the interior of the cyst was found in a sloughing condition, and the structure surrounding it presented all the appearances of what Sir James Paget describes as a very rare disease in this country, although he says it is not uncommonly met with in France, Germany, and America-viz., medullary cancer of the female breast. (Vide Paget's Surg. Path., edited by Professor Turner, p. 657.)

Mr. LuKn Armstrong removed, by lateral lithotomy, an oxalate-of-lime calculus, weighing ninety-eight grains, coated with phosphates, from the bladder of a man aged twenty-four years, who had suffered from urinary irritation from birth. The patient is undersized, somewhat weakminded, and both his femora are rickety.

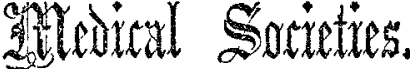

\section{CLINICAL SOCIETY OF LONDON,}

Friday, OCT. 13Th, 1871.

Dr. W. W. Guld, F.R.S., President, in the Chair.

THere was a fair attendance of members at this, the first meeting of the session, and a few introductory remarks were made by the President.

Dr. BAUMLER read a paper on Partial and General Idiopathic Pericarditis, in which he endeavoured to prove that the white or milky spot on the surface of the heart frequently met with at post-mortem examinations has a clinical history of very transient acute pericarditis. He adduced in support of this proposition two cases, in which an acute illness, coming on with dyspncea, with pain behind the sternum, radiating upwards to the larnyx, the left shoulder, and towards the left ear, and with slight febrile disturbance, was accompanied by a characteristic pericardial friction-sound, lasting, like the other symptoms, only for two or three days. In a third case, where the onset had been more gradnal, the friction-sound was heard over a larger area; and there was also some distension of the pericardium by fluid; yet the whole attack was mild and lasted only a fortnight. Such intermediate forms link the very slight cases to the more serious ones, which more generally come under observation. Cases of idiopathic pericarditis being of rare occurrence, Dr. Baumler appended the history of three other cases of this kind which had come under his observation. The three patients had been little girls from eight to ten years of age, and the pericarditis had come on in so insidious a manner that they had walked about with the pericardium full of effusion. One cf them died; the two others recovered, one entirely, the other with valvular disease remaining. With regard to treatment, Dr. Bäumler particularly recommended the application of ice to the cardiac region, especially for its influence in reducing the number of the heart's contractions and in relieving pain.

The PRESIDENT remarked that, among other points of interest in connexion with this subject, it has been a matter of doubt as to whether genuine pericarditis, per se, ever causes pain, and that some so-called cases of the disease had proved to be cases of pleurisy, the frictionsound being due to a pleuritic xubbing immediately over the pericardium.

Dr. Douglas Powell asked Dr. Bäumler how the treatment of ice-bags could be reconciled with the intermittent application of linseed and mustard poultices.

Dr. C. T. Wrusrams asked for particulars as to the influence of ice-bags on the pulse and heart.

Dr. BAUMLER replied that, according to his knowledge and belief, the application of ice-bags acts antiphlogistically, reducing both pulse and temperature, and that the poultices were used, in the absence of other remedial agents, because in an empirical way they relieved pain.

Mr. Nunn read a paper on Lupus Frythematosus. This disease, known also as superficial lupus, was believed by Mr. Nunn to be essentially an inflammatory atroply of the cutis, limitios itselr to that structure, and thus distinguished from lupus exedens, which was capable apparently of destroying indiscriminately every structure. Two 